\title{
Diaphragmatic Electromyogram Power-Spectral Analysis as a Function of Reduced End- Expiratory Lung Volume
}

\author{
A. LANTZY, T. L. O'DAY, R. L. VAZQUEZ, R. D. GUTHRIE, AND J. F. WATCHKO \\ Department of Pediatrics, University of Pittsburgh School of Medicine, Magee-Womens Hospital, \\ Pittsburgh, Pennsylvania 15213
}

\begin{abstract}
We examined the centroid frequency $(\mathrm{Fc})$ of the electromyogram power-frequency spectra from the costal (EMGco) and crural (EMGcr) diaphragms at functional residual capacity and at reduced end-expiratory lung volume (EELV) (induced by abdominal banding) in six anesthetized newborn piglets. EMGco and EMGcr were recorded from bipolar electrodes embedded in the costal and crural diaphragms respectively. A fast Fourier transformation of ECG free EMGco and EMGcr was used to compute the power-frequency spectra and calculate the $\mathrm{Fc}$ of EMGco and EMGcr. The nitrogen washout technique was used to measure EELV. Abdominal banding induced a reduction in EELV of $30.6 \%$ functional residual capacity (range 22-39\%). The mean Fc of EMGcr was not significantly altered by the reduction in EELV, whereas the mean Fc of the EMGco fell in every animal at reduced EELV by $13 \pm 8 \%$ of baseline Fc $(p<0.05)$. We conclude that alterations in lung volume alone can determine changes in the EMGco power spectrum and Fc. Investigators performing EMGco power spectral analysis should consider EELV status when interpreting their findings. (Pediatr Res 30: 606-609, 1991)
\end{abstract}

\section{Abbreviations}

EELV, end-expiratory lung volume

EMG, electromyogram

EMGco, costal diaphragm electromyogram

EMGcr, crural diaphragm electromyogram

Fc, centroid frequency

FRC, functional residual capacity

Pdi, transdiaphragmatic pressure

Diaphragmatic EMG power-frequency spectral analysis has been used to index diaphragmatic fatigue in newborns $(1-3)$ and adults (4). Such analysis involves EMG monitoring in which the power or amplitude of the EMG signal is examined as a function of its various frequency components (5). The assignment of the label diaphragmatic fatigue rests on the observation that fatigue in limb skeletal muscle is associated with characteristic changes in the power of the EMG frequency components. These changes include 1) a rapid decrease in high-frequency power, 2) a progressive increase in low frequency power, and 3) a fall in the centroid or median frequency and high-to-low frequency ratio $(6,7)$.

Received February 22, 1991; accepted July 15, 1991

Correspondence: Jon F. Watchko, M.D., Division of Neonatology, Department of Pediatrics, Magee-Womens Hospital, Forbes Avenue and Halket Street, Pittsburgh, PA 15213.

Supported by a grant from the West Penn Hospital Foundation.
EMG power-frequency spectral analysis, however, can be affected by various changes in the environmental milieu of the muscle including alterations in ambient temperature (8), $\mathrm{pH}(9)$, and muscle blood flow (8) and by changes in muscle length/ configuration $(10,11)$. Few of these physiologic alterations have been examined with reference to the diaphragm $(9,12)$. No investigation has examined the effect of changes in lung volume (and, by inference, diaphragm length/configuration) on the EMG power-frequency spectrum of this muscle. Studies on appendicular muscle have demonstrated that EMG power shifts to lower frequencies with increasing muscle length $(10,11)$. In this regard, an increase in diaphragm length occurs when EELV is reduced (13-15). We, therefore, examined the effect that reductions in EELV have on the power-frequency spectrum of the costal and crural diaphragm of piglets. We hypothesized that a reduction in EELV would be associated with a significant decline in the EMG Fc of both the costal and crural diaphragm.

\section{MATERIALS AND METHODS}

Farm bred piglets, obtained from a local breeder who provided accurate times of farrowing, served as our study animals. Experiments were performed on six 1- to 3 -d-old (weight $1.8 \pm 0.2 \mathrm{~kg}$ ) piglets. Anesthesia was induced with halothane (1.0\%) delivered in a background of $40 \% \mathrm{O}_{2}$ via a securely fitting face mask. After cannulation of the femoral artery and vein, anesthesia was maintained with an i.v. combination of $\alpha$-chloralose $(50 \mathrm{mg} / \mathrm{kg})$ and urethane $(200 \mathrm{mg} / \mathrm{kg})$; halothane administration was discontinued. Subsequent infusions of chloralose and urethane were given if the piglet developed jaw clonus. The trachea was surgically exposed and cut horizontally. A 3-mm inner diameter endotracheal tube with adapter was inserted in the distal trachea, secured with suture, and attached to a Hans-Rudolph (Kansas City, MO) miniature two-way nonrebreathing valve (no. 2384). A Corning 168 blood gas analyzer (Corning Glass Works, Medfield, MA) was used to determine blood gas tensions and $\mathrm{pH}$. Rectal temperature was continuously monitored (Tele-Thermometer 43TA; Yellow Springs Instrument Co., Yellow Springs, $\mathrm{OH}$ ) and maintained between 38.5 and $39.5^{\circ} \mathrm{C}(16)$ with a heated water mattress (Aquamatic model K-20; American Hospital Supply, Cincinnati, $\mathrm{OH})$ and a radiant warmer.

Bipolar, Teflon-insulated, multistranded stainless steel wire electrodes (0.01 inch diameter) with the distal $1-2 \mathrm{~mm}$ bared (Cooner Wire, Chatsworth, CA) were inserted into the ventral paratendinous costal diaphragm $(n=6)$ and the midportion of the crural diaphragm $(n=5)$. Access to the costal diaphragm was obtained by a subcostal extraperitoneal incision. Costal electrode placement was performed under direct vision with wires placed approximately $2 \mathrm{~mm}$ apart oriented parallel to the direction of the costal diaphragm muscle fibers. After placement of the costal diaphragm electrode, the surgical incision was closed. The crural electrode was placed percutaneously using 21 -gauge 
spinal needles as previously described $(17,18)$. This percutaneous approach was used to secure crural EMG signals because direct surgical placement was considered too invasive in this small animal. Postmortem examination indicated that the electrodes were embedded within the crura less than $10 \mathrm{~mm}$ from one another. A third electrode was placed subdermally in the right thigh to provide an electrical ground. Electrode placement was unilateral and on the right side in all the study animals. All animals were studied in the supine position.

Costal and crural EMG signals were recorded differentially to ground and amplified $1-10 \times 10^{3}$ times by a preamplifier (BMA830 Head Stage Amplifier; Charles Ward Electronics, Ardmore, PA) before recording on FM tape (Gould Electronics, Cleveland, $\mathrm{OH}$; model 6508). The EMG signal was processed using a Service Associates 414 analog processor (Encinitas, CA), where it was filtered to allow passage of frequencies between 30 and $3000 \mathrm{~Hz}$. The EMG was full-wave rectified and integrated through a Paynter filter with a 100 -ms time constant to obtain moving time average EMG (19). In addition, an ECG signal was monitored and recorded on the FM tape via two wire electrodes placed in the chest wall. Raw and processed signals were displayed on a Tektronix 511A storage oscilloscope (Tektronix, Inc., Beaverton, OR) during the study.

The fast Fourier transform and the Fc of the costal and crural EMG signals were obtained using a Hewlett-Packard Dynamic Signal Analyzer (model 3561A; Palo Alto, CA) as previously described (20). EMG signals free of ECG artifact were used for this analysis. To eliminate ECG artifact from the EMG, a gating device (EKG Blanker, model SB-1; Charles Ward Electronics) was used and the gated EMG signal was visually examined on a digital oscilloscope (Gould model 1602) before further processing.

The frequency span of the entire power spectrum was from 0 to $1000 \mathrm{~Hz}$, resulting in a spectral time record duration of 400 ms and a display resolution of $2.5 \mathrm{~Hz}$. The EMG signals were sampled at a rate of 2560 to satisfy the Nyquist requirement and minimize aliasing (5). A Hanning window was used to minimize leakage (5). High-pass filtering at $30 \mathrm{~Hz}$ was used to minimize motion artifact (5). The $\mathrm{Fc}_{\mathrm{c}}$ was computed from the power frequency spectrum between 30 and $500 \mathrm{~Hz}$. Previous work has established that $>95 \%$ of inspiratory diaphragmatic EMG power in piglets is contained between these two frequencies (21). The Fc was calculated and defined as the frequency at which the power above and below it were equal (5). A minimum of 20 consecutive breaths were analyzed and averaged for any given study period to ensure that all inspiratory times were sampled sufficiently to establish the predominant frequency components of the associated EMG.

EELV measurements were obtained using the nitrogen washout technique as adapted for use in small animals (22) and previously used in piglet studies $(21,23,24)$. EELV measurements obtained during the baseline period were designated as FRC.

After surgery and a 30 -min equilibration period, baseline 1 ) costal and crural EMG recordings, 2) FRC measurements and 3) an arterial blood gas were obtained. Reductions in EELV were accomplished using a standard blood pressure cuff placed around the abdomen (leaving the lower rib cage exposed) and gently inflated to $35-40 \mathrm{~mm} \mathrm{Hg}$ for a period of $5 \mathrm{~min}$. Continuous costal and crural EMG recordings, an EELV measurement, and an arterial blood gas were obtained during this period of blood pressure cuff inflation. The blood pressure cuff was then deflated, and costal and crural EMG recordings, an EELV measurement, and an arterial blood gas were obtained.

Previous studies on piglets have consistently demonstrated an augmentation of diaphragmatic force output during acute reductions in $\operatorname{EELV}(21,24)$. However, to ensure that abdominal binding did not induce a decline in diaphragmatic force output, i.e. diaphragmatic fatigue, we examined Pdi (an index of diaphragmatic force output) generated during phrenic nerve stimu- lation in two piglets with the abdomen bound (blood pressure cuff inflated to $35-40 \mathrm{~mm} \mathrm{Hg}$ ) and unbound (blood pressure cuff on abdomen but deflated). Pdi was generated using the transvenous phrenic nerve stimulation technique previously described $(21,24)$. Briefly, the phrenic nerves were stimulated (model S48 stimulator; Grass Medical Instruments, Quincy, MA) via bilateral indwelling external jugular vein catheter electrodes at supramaximal voltage at 30,50 , and $100 \mathrm{~Hz}$. A thin-walled, latex rubber balloon (Youngs Rubber, Trenton, NJ) containing $0.5 \mathrm{~mL}$ of air was connected to a polyethylene catheter (1.65 $\mathrm{mm}$ inner diameter) and placed in the stomach to measure gastric pressure. Proximal airway pressure was measured via an 18-gauge needle inserted in the tracheostomy tube proximal to the nonrebreathing valve. Because proximal airway pressure reflects intrapleural pressure more accurately during phrenic nerve stimulation than esophageal pressure (25), Pdi was measured, using a differential pressure transducer (Validyne, Northridge, $\mathrm{CA}$ ), as Pdi = gastric pressure - proximal airway pressure.

Analysis of variance as well as paired two-tailed $t$ tests were used for statistical analysis of the data as appropriate (Minitab Data Analysis Software, Standard Version Release 5.1.3., Minitab, State College, PA). $p<0.05$ was considered statistically significant. Data for all animals are reported as means \pm SD.

\section{RESULTS}

Arterial blood gas determinations obtained during eupnea with the abdomen unbound and during abdominal binding are shown in Table 1 . No significant differences were noted in $\mathrm{pH}$, arterial $\mathrm{CO}_{2}$ tension, arterial $\mathrm{O}_{2}$ tension, or base excess between these two conditions.

Abdominal binding induced 1) a significant decline in EELV in each animal as shown in Table $2(p<0.05)$ and 2$)$ an augmentation in Pdi at each frequency of phrenic nerve stimulation (Pdi expressed as a percentage of baseline: $30 \mathrm{~Hz}, 136 \pm$ $34 \% ; 50 \mathrm{~Hz}, 136 \pm 15 \% ; 100 \mathrm{~Hz}, 124 \pm 10 \%$ ). The magnitude of the reduction in EELV was $30.6 \pm 7 \%$ of FRC (range 22$39 \%)$.

The mean Fc of EMGcr was not significantly altered by the reduction in EELV as seen in Table 3 . In contrast, the mean Fc

Table 1. Arterial blood gas determinations*

\begin{tabular}{ccccc}
\hline & & & & Base \\
& $\mathrm{pH}$ & \multicolumn{1}{c}{$\mathrm{PaCO}_{2}$} & \multicolumn{1}{c}{$\mathrm{PaO}_{2}$} & excess \\
\hline FRC & $7.36 \pm 0.03$ & $6.4 \pm 0.7 \mathrm{kPa}$ & $16.5 \pm 9.3 \mathrm{kPa}$ & $1 \pm 1$ \\
& & $(48 \pm 5 \mathrm{torr})$ & $(124 \pm 70$ torr $)$ & \\
Reduced & $7.33 \pm 0.06$ & $6.6 \pm 1.5 \mathrm{kPa}$ & $22.6 \pm 15.7 \mathrm{kPa}$ & $1 \pm 1$ \\
EELV & & $(50 \pm 11$ torr $)$ & $(170 \pm 118$ torr $)$ & \\
\hline
\end{tabular}

* $\mathrm{PaCO}_{2}$, arterial $\mathrm{CO}_{2}$ tension; $\mathrm{PaO}_{2}$, arterial $\mathrm{O}_{2}$ tension.

Table 2. EELV measurements

\begin{tabular}{cccc}
\hline Animal no. & FRC $(\mathrm{cc})$ & Reduced EELV $(\mathrm{cc})$ & \% Change \\
\hline 1 & 26.4 & 17.0 & $\downarrow 35.6$ \\
2 & 55.8 & 41.2 & $\downarrow 26.0$ \\
3 & 28.6 & 22.2 & $\downarrow 22.0$ \\
4 & 57.6 & 35.0 & $\downarrow 39.0$ \\
5 & 62.2 & 44.8 & $\downarrow 27.0$ \\
6 & 73.8 & 48.6 & $\downarrow 34.0$ \\
Mean & $50.7 \pm 19$ & $34.8 \pm 13$ & $\downarrow 30.6 \pm 7$ \\
\hline
\end{tabular}

Table 3. Crural diaphragm $F_{C}$ measurements

\begin{tabular}{cccc}
\hline Animal no. & FRC $(\mathrm{Hz})$ & Reduced EELV $(\mathrm{Hz})$ & \% Change \\
\hline 1 & 141 & 153 & $\uparrow 8$ \\
2 & 174 & 191 & $\uparrow 9$ \\
3 & 114 & 118 & $\uparrow 4$ \\
4 & 267 & 265 & $\downarrow 1$ \\
5 & 132 & 128 & $\downarrow 3$ \\
\hline
\end{tabular}


Table 4. Costal diaphragm Fc measurements

\begin{tabular}{cccc}
\hline Animal no. & FRC $(\mathrm{Hz})$ & Reduced EELV $(\mathrm{Hz})$ & \% Change \\
\hline 1 & 148 & 129 & $\downarrow 13$ \\
2 & 135 & 125 & $\downarrow 7$ \\
3 & 106 & 94 & $\downarrow 11$ \\
4 & 269 & 202 & $\downarrow 25$ \\
5 & 259 & 212 & $\downarrow 18$ \\
6 & 334 & 322 & $\downarrow 4$ \\
\hline
\end{tabular}

of EMGco declined in every animal at reduced EELV (Table 4) by $13 \pm 8 \%$ of its baseline value $(p<0.05)$.

After the discontinuation of abdominal binding, the numeric values of the EMGco and EMGcr Fc and EELV returned to baseline values.

\section{DISCUSSION}

The results of this study demonstrate that a significant decline in the numeric value of the costal diaphragm Fc occurs in association with acute reductions in EELV but no change in arterial blood gas measurements. In contrast, the Fc of the crural diaphragm was not appreciably altered by such changes in lung volume. The observed decline in costal diaphragm Fc was not secondary to "fatigue," inasmuch as our results and those of previous studies have documented an augmentation of diaphragmatic force output during acute reductions in $\operatorname{EELV}(21,24,26$, 27).

Costal diaphragm Fc. The decline in the EMGco Fc at reduced EELV is consistent with work on appendicular skeletal muscle $(10,11)$-work that may provide an explanation for our observations. Studies on appendicular muscle demonstrate that changes in muscle length alone can have a profound effect on the distribution of power within an EMG's power-frequency spectrum $(10,11)$ and, more specifically, that EMG power shifts to lower frequencies with increasing muscle length. In this regard, the length of the diaphragm is a function of lung volume, with increases in diaphragm length occurring with declines in EELV (13-15). When lung volume falls and the diaphragm lengthens, diaphragm thickness is reduced (28). This decrease in muscle thickness causes a decline in action potential conduction velocity (29) that results in a fall in high-frequency power content (30) and, thus, a decline in the numeric value of the Fc (11).

It should be noted that the induced reductions in EELV used in our study were on the order of $30 \% \mathrm{FRC}$. This was a significant reduction in EELV but one that was well tolerated by the animals and not associated with any alterations in arterial blood gas measurements. Mayock et al. (21) have demonstrated a similar degree of EELV reduction ( $40 \%$ FRC) in the piglet during periods of inspiratory resistive loaded breathing and Watchko et al. (24) reported reductions in EELV of approximately $25 \%$ FRC during periods of heightened respiratory drive induced by carbon dioxide breathing in this same animal model. Moreover, our induced reductions in EELV were well within the expiratory reserve volume range estimates reported for human newborns of $35-45 \%$ FRC $(31,32)$. Thus, the reduction in EELV used in our study can be characterized as physiologic.

Crural diaphragm $F c$. The numeric value of the EMGcr Fc was not significantly altered by reductions in EELV. The reason for this observation is unclear. The crural diaphragm, like the costal diaphragm, lengthens in response to a fall in EELV, although study results differ in regard to the degree of crural lengthening relative to costal lengthening under such conditions (13-15). Most studies, but not all (14), demonstrate greater costal lengthening when compared with the crura during induced reductions in $\operatorname{EELV}(13,15)$. These investigations of lung volume/ diaphragm length changes have been performed in adult dogs. If a similar relative costal/crural lengthening relationship at reduced EELV exists in the newborn piglet, then these findings could explain in part the differential changes in costal and crural Fc.

Alternatively, electrode configuration is known to affect the EMG power-frequency spectrum with interelectrode distance of the bipolar electrode being an important variable (33). In particular, as interelectrode distance is increased, more relative power is contained in the low-frequency range (34), making bipolar electrodes with large interelectrode distances less sensitive to decreases in high-frequency power or increases in low-frequency power $(34,35)$, the two changes that contribute to a decline in Fc. The interelectrode distance of the crural diaphragm bipolar electrode was approximately $10 \mathrm{~mm}$, an appreciably greater interelectrode distance than that of the costal diaphragm electrode $(2 \mathrm{~mm})$ (see Materials and Methods). Thus, the large interelectrode distance of the crural diaphragm bipolar electrode may account in part for the failure to observe any Fc changes at reduced EELV in the crural diaphragm in our study.

Diaphragmatic EMG power spectral analysis and diaphragmatic fatigue. Diaphragmatic EMG power spectral analysis has been used and continues to be promoted as a method for indexing diaphragmatic fatigue in newborns $(1-3,36,37)$ and adults $(4$, $38,39)$. The results of our study are relevant to an understanding of the limitations of this method because they indicate that alterations in lung volume can determine changes in the EMG power spectrum and centroid frequency independently of fatigue. Moreover, these findings are clinically relevant because a frequent compensatory measure to meet an increased work load demand on the diaphragm is to actively reduce EELV (by recruiting abdominal muscle expiratory activity) and lengthen the diaphragm in an attempt to maintain inspiratory force output $(21,24,40-42)$. Such changes in lung volume would likely be associated with a shift of power within the diaphragmatic EMG power-frequency spectrum to lower frequencies, as demonstrated in our study, and would falsely indicate "fatigue." Indeed, Sieck et al. (43) have documented shifts in the EMGco power spectrum to lower frequencies during trials of voluntary hyperpnea that were well tolerated and not associated with the development of ventilatory failure, i.e. EMG power spectral shifts to lower frequencies occurred in the absence of "fatigue" (a false-positive shift). The results of our study would suggest that this decline in the EMGco Fc was mediated by reductions in EELV known to occur during hyperpneic states $(21,24,40)$.

Other experimental work suggests that false-negative results can also be obtained using EMG analysis, i.e. diaphragmatic fatigue can occur and yet fail to be indexed by a shift in the diaphragmatic EMG Fc. In this regard, Mayock et al. (21) have observed a lack of diaphragmatic EMG power-frequency spectral shifts in piglets during ventilatory failure induced by severe inspiratory resistive loaded breathing despite a decline in diaphragmatic force output (21). Similarly, Kongragunta et al. (44) have reported objective evidence of diaphragmatic fatigue in adults with chronic obstructive pulmonary disease during trials of loaded breathing in which the diaphragmatic EMG powerfrequency spectrum remained stable (44). Thus, the validity of diaphragmatic EMG power-frequency spectral shifts to predict diaphragmatic fatigue remains uncertain.

Finally, it is of interest that most investigations relating diaphragmatic EMG power-frequency spectral shifts to lower frequencies with diaphragmatic fatigue have not combined diaphragmatic EMG analysis with determinations of 1) central neural drive to the diaphragm and 2) diaphragmatic force output, nor have they addressed the temporal relationship among these three variables. An exception is a study by Bazzy and Haddad (45) in which all three variables (EMG power-frequency spectrum, central neural drive, and diaphragmatic force output) were monitored (45). These investigators demonstrated that diaphragmatic EMG power spectral shifts were associated with a decline in central neural drive, both of which occurred before a decline in diaphragmatic force output. These data point to a possible central mechanism as the etiology for diaphragmatic force output 
impairment and the observed diaphragmatic EMG power spectral shift. Others have recently suggested the same conclusion $(34,45,46)$.

In summary, our data demonstrate that EMGco power-frequency spectral shifts can be induced by acute reductions in EELV. The observed decline in costal diaphragm Fc was not secondary to "fatigue," but likely reflects costal diaphragmatic lengthening at the lower EELV. We conclude that caution is warranted in using diaphragmatic EMG power-frequency spectral analysis to predict diaphragmatic fatigue. Further investigation is needed to clarify the relationship between diaphragmatic EMG and mechanical activities during ventilatory failure.

Acknowledgments. The authors thank Maureen Davis and Sue Scheeren for assistance in preparation of the manuscript as well as Thomas A. Standaert, Ph.D., and Dennis E. Mayock, M.D., for their assistance and technical advisement.

\section{REFERENCES}

1. Muller N, Gulston G, Cade D, Whitton J, Froese AB, Bryan MH, Bryan AC 1979 Diaphragmatic muscle fatigue in the newborn. J Appl Physiol 46:688 695

2. Muller NL, Volgyesi G, Bryan MH, Bryan AC 1979 The consequences of diaphragmatic muscle fatigue in the newborn infant. J Pediatr 95:793-797

3. Chambille B, Vardon G, Monrigal JP, Dehan M, Gaultier C 1989 Technique of on-line analysis of diaphragmatic electromyogram activity in the newborn. Eur Respir J 2:883-886

4. Moxham J, Edwards RHT, Aubier M, DeTroyer A, Farkas G, Macklem PT, Roussos C 1982 Changes in EMG power spectrum (high-to-low ratio) with force fatigue in humans. J Appl Physiol 53:1094-1099

5. Schweitzer TW, Fitzgerlad JW, Bowden JA, Lynne-Davies P 1979 Spectral analysis of human inspiratory diaphragm electromyograms. J Appl Physio 46:152-165

6. Kadeffors R, Kaiser E, Petersen I 1968 Dynamic spectrum analysis of myopotentials and with special reference to muscle fatigue. Electromyography $8: 39$ 74

7. Lindstrom L, Kadeffors R, Petersen I 1977 An electromyographic index for localized muscle fatigue. J Appl Physiol 43:750-754

8. Merletti R, Sabbahi MA, DeLuca CJ 1984 Median frequency of the myoelectric signal: effects of ischemia and cooling. Eur J Appl Physiol 52:258-265

9. Pollock M, Brody L, Roy SH, DeLuca CJ, Celli B 1990 Effect of uncompensated and compensated respiratory acidosis on force and electromyographic median frequency in the hamster diaphragm. FASEB J 4:A864(abstr)

10. Bazzy AR, Kortern JB, Haddad GG 1986 Increase in electromyogram lowfrequency power in non-fatigued contracting skeletal muscle. J Appl Physiol 61:1012-1017

11. Shankar S, Gander RE, Brandell BR 1989 Changes in the myoelectric signal (MES) power spectra during dynamic contractions. Electroencephalogr Clin Neurophysiol 73:142-150

12. Choukroun ML, Kays C, Varene $P 1990$ EMG study of respiratory muscles in humans immersed at different water temperatures. J Appl Physiol 68:611616

13. Margulies SS, Farkas GA, Rodarte JR 1990 Effects of body position and lung volume on in situ operating length of canine diaphragm. J Appl Physiol 69:1702-1708

14. Decramer M, Xi JT, Reid MB, Kelly S, Macklem PT, Demedts M 1986 Relationship between diaphragm length and abdominal dimensions. J Appl Physiol 61:1815-1820

15. Farkas GA, Rochester DF 1988 Functional characteristics of canine costal and crural diaphragm. J Appl Physiol 65:2253-2260

16. Mount LE, Ingram DL 1971 Physiology. In: The Pig as a Laboratory Animal. Academic, New York, pp 65-78

17. Trelease RB, Sieck GC, Harper RM 1982 A new technique for acute and chronic recording of crural diaphragm EMG in cats. Electroencephalogr Clin Neurophysiol 53:459-462

18. Watchko JF, Mayock DE, Standaert TA, Woodrum DE 1987 Effect of hypercapnia and hypoxia on costal and crural diaphragm electromyograms in piglets. Pediatr Res 23:54-57
19. Lopata M, Evanich MJ, Lourenco RV 1977 Quantification of diaphragmatic EMG response to $\mathrm{CO}_{2}$ rebreathing in humans. J Appl Physiol 43:262-270

20. Watchko JF, Standaert TA, Mayock DE, Twiggs G, Woodrum DE 1988 Ventilatory failure during loaded breathing: the role of central neural drive J Appl Physiol 65:249-255

21. Mayock DE, Standaert TA, Murphy TD, Woodrum DE 1991 Diaphragmatic force and substrate response to resistive loaded breathing in the piglet. $J$ Appl Physiol 70:70-76

22. Standaert TA, LaFramboise WA, Tuck RE, Woodrum DE 1985 Serial determination of lung volume in small animals by nitrogen washout. $J$ Appl Physiol 59:205-210

23. Watchko JF, LaFramboise WA, Standaert TA, Woodrum DE 1986 Diaphrag matic function during hypoxemia: neonatal and developmental aspects. J Appl Physiol 60:1599-1604

24. Watchko JF, Standaert TA, Woodrum DE 1987 Diaphragmatic function during hypercapnia: neonatal and developmental aspects. J Appl Physiol 62:768-775

25. Mayock DE, Watchko JF, Standaert TA, Woodrum DE 1990 Estimation of intrapleural pressure in the newborn. Pediatr Pulmonol 9:30-33

26. Mier A, Brophy C, Moxham J, Green M 1990 Influence of lung volume and rib cage configuration on transdiaphragmatic pressure during phrenic nerve stimulation in man. Respir Physiol 80:193-202

27. Smith J, Bellemare F 1988 Effect of lung volume on in vivo contraction characteristics of the human diaphragm. In: Grassino A, Fracchia C, Rampulla C, Zocchi L (eds) Respiratory Muscles in COPD. Springer-Verlag, London, pp 95-110

28. Wait JL, Nahormek PA, Yost WT, Rochester DP 1989 Diaphragmatic thickness-lung volume relationship in vivo. J Appl Physiol 67:1560-1568

29. Inbar GF, Allin J, Golos E, Koehler W, Kranz H 1981 EMG spectral shift with muscle length, tension and fatigue. Proc IEEE Melecon Conference, Israel 8.2.3:1-5

30. Lindstrom LH, Magnusson RI, Petersen I 1970 Muscular fatigue and action potential conduction velocity changes studied with frequency analysis of EMG signals. Electromyography 8:341-356

31. Nelson NM 1966 Neonatal pulmonary function. Pediatr Clin North Am 13:769-799

32. Godfrey S 1974 Growth and development of the respiratory system: functiona development. In: Davis JA, Dobbing J (eds) Scientific Foundations of Paediatrics. WB Saunders, Philadelphia, pp 254-271

33. Basmajian JV, DeLuca C 1985 Apparatus, detection and recording techniques In: Muscles Alive: Their Functions Revealed by Electromyography. Williams \& Wilkins, Baltimore, pp 19-64

34. Lynn PA, Bettles ND, Hughes AD, Johnson SW 1978 Influences of electrode geometry on bipolar recordings of surface electromyogram. Med Biol Eng Comput 16:651-660

35. Petrozzino JT, Scardella AT, Li JKJ, Krawciw N, Edelman NH, Santiago TV 1990 Effect of naloxone in spectral shifts of the diaphragm EMG during inspiratory loading. J Appl Physiol 68:1376-1385

36. Lopes JM, Muller NL, Bryan MH, Bryan AC 1981 Synergistic behavior of respiratory muscles after diaphragmatic fatigue in the newborn. $\mathrm{J}$ Appl Physiol 51:547-551

37. Monrigal JP, Chambille B, Praud JP, Saby MA, Dehan M, Gaultier C 1988 Can diaphragmatic centroid frequency analysis help in weaning artificially ventilated infants? Eur Respir J 1(suppl):55S

38. Gross E, Grassino A, Ross WRD, Macklem PT 1979 Electromyogram pattern of diaphragmatic fatigue. J Appl Physiol 46:1-7

39. Scano G 1990 Respiratory muscle fatigue. Eur Respir J 3:970-973

40. Loring SH, DeTroyer A 1985 Actions of the respiratory muscles. In: Roussos C, Macklem PT (eds) The Thorax. Marcel Dekker, New York, pp 327-349

41. South M, Morley CJ, Hughes G 1987 Expiratory muscle activity in preterm babies. Arch Dis Child 62:825-829

42. Watchko JF, O'Day TL, Brozanski BS, Guthrie RD 1990 Expiratory abdominal muscle activity during ventilatory chemostimulation in piglets. J Appl Physiol 68:1343-1349

43. Sieck GC, Mazar A, Belman MJ 1985 Changes in diaphragmatic EMG spectra during hyperpneic loads. Respir Physiol 61:137-152

44. Kongragunta VK, Druz WS, Sharp JT 1988 Dyspnea and diaphragmatic fatigue in patients with chronic obstructive pulmonary disease. Am Rev Respir Dis 137:662-667

45. Bazzy AR, Haddad GG 1984 Diaphragmatic fatigue in unanesthetized adult sheep. J Appl Physiol 57:182-190

46. Jammes Y, Balzamo YE, Gardette $\mathrm{MCl}$, Tomei Ch 1990 Electrically-induced diaphragm fatigue and reflex changes in the ventilatory control in cats. International Conference on the Modulation of Respiratory Pattern: Peripheral and Central Mechanisms, Lexington, KY, p 94(abstr) 